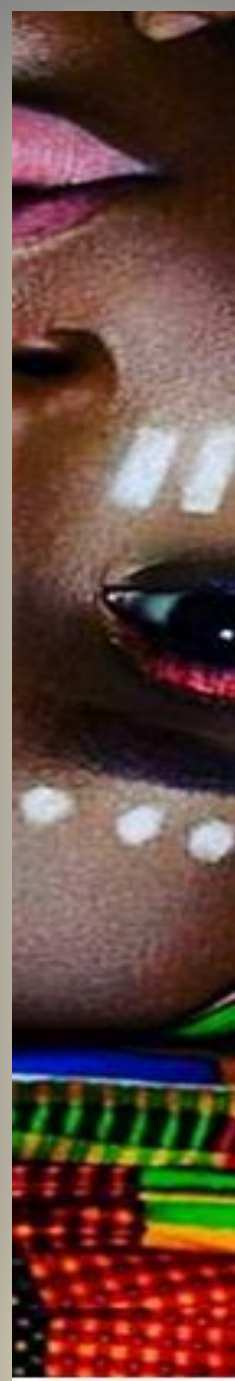

\title{
Carta aos leitores
}

Sejam bem vindos a este número que busca estimular nosso pensar sobre as relações entre corpo, território e educação.

Abrimos esta edição com a autora convidada, filósofa e professora Silmara Lidia Marton, que nos dá a pensar através de reflexões que articulam o cinema de David Mackenzie, mais especificamente o filme Os sentidos do amor, à educação. Aqui, arte e filosofia assumem "a tarefa de provocar a expressão primordial do sentir-pensar" como possibilidade de abertura para nosso entendimento do mundo. Apoiada na fenomenologia de Merleau-Ponty, Marton traz à cena o protagonismo do sentido em oposição à supremacia de uma racionalidade lógica que supõe dominar os objetos, desprezando nossas percepções corpóreas.

O fato é que ninguém determinou, até agora, o que pode o corpo, isto é, a experiência a ninguém ensinou, até agora, o que o corpoexclusivamente pelas leis da natureza enquanto considerada apenas corporalmente, sem que seja determinado pela mente - pode e o que não pode fazer (Espinosa - Ética III, Prop. 2).

Começamos a abordar o Dossiê Temático em diálogo com o filósofo holandês Baruch Espinosa que coloca em questão os princípios racionalistas que, desde Platão passando por Reneé Descartes, desembocaram na razão dominante ainda presente nas escolas ocidentais. Nós, editoras da Revista Aleph, defendemos que não há caminho para o conhecimento sem que sejamos atravessadas por experiências corpóreas, visto que nossas escolas têm desprezado o corpo como fonte e acesso ao conhecimento, como confirmam algumas das pesquisas apresentadas em nosso Dossiê. A razão não está acima do corpo, como acreditavam Platão e Aristóteles, tão pouco fora do corpo, como pensava Descartes, mas sim no próprio corpo, nos bons e potentes encontros entre corpos.

Os movimentos de territorialização, desterritorialização e reterritorialização provocam danças entre corpos que cartografam relações culturais, desenhando e redesenhando as sociedades nos convocando a reflexões sobre como essas impressões nos corpos têm denunciado processos de colonização, desde as explorações do mercado às padronizações pelas mídias e instituições. Modos que silenciam ou criam moldagens estereotipadas nos modos de ser e nos processos educacionais, dentro e fora da escola.

Os atuais modos de produção e consumo provocam representações simbólicas que ao se infiltrarem nas culturas, podem gerar desagregação entre corpo e sentido, mas também, podem produzir resistências, resiliências e buscas instituintes por formas mais inclusivas e includentes das diferenças: de gênero, de origem social, de faixa etária, de grupo étnico, de afetividade sexual, de religião e até de maneira de vestir e se comportar em em uma determinada profissão ...

Apostamos em um mundo no qual a educação possa instituir novas lógicas, novas possibilidades de sermos aquilo que nossos sonhos e desejos almejam, contrariando os apelos que a racionalidade econômica e a moral dominantes têm exigido de uns e de outros, territorializando-nos em lugares fixos e rotulando indivíduos e grupos sem espaço para refletirem que são as diferenças que estruturam a vida social. A diferença é, simultaneamente, a base da vida social e fonte permanente de tensão e conflito, escreveu Gilberto Velho (2008). A interação entre diferenças e diferentes nos desterritorializa e possibilita que o indivíduo reafirme aquilo que faz parte de si mesmo e o que faz parte do mundo social. Chegamos, então, a questão da relação eu-outro, a alteridade necessária para a estruturação de uma "ética do corpo" que vai além da estetização, mas não pode com ela romper, na medida em que se interpenetram na construção de nossas maneiras de sentir e perceber o mundo. Nesta edição são doze artigos que compõem o dossiê temático Culturas, Corpo e Educação: descolonizando relações. 


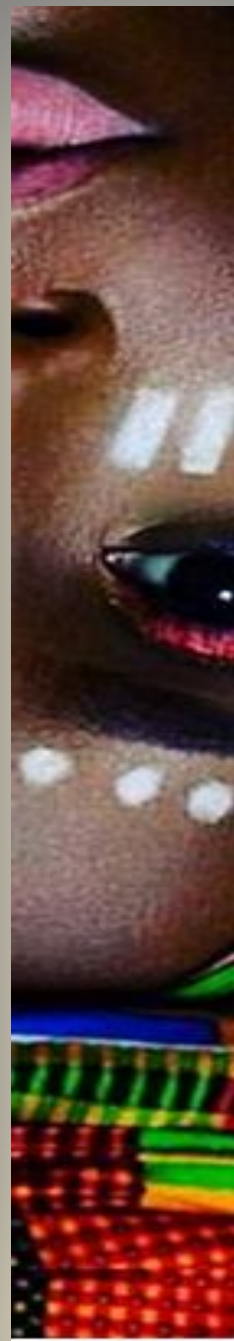

Na seção Pulsações e Questões contemporâneas publicamos dez artigos que instigam o pensar possibilitando-nos ampliar a compreensão sobre os movimentos que podem vir a gerar transformaçoes culturais e mudanças sócio-politicas em nosso tempo, que impulsionam novos caminhos para estudos e propostas educacionais.

Nesse sentido, oferecemos aos leitores uma série de trabalhos que abrangem desde o debate internacional sobre a formação e valorização da profissão docente, até contribuições nacionais relativas à questão da imigração, da transição entre Educação Infantil e Ensino Fundamental na dinâmica da formação docente. Importante destacar o caleidoscópio teórico que os artigos apresentam, fruto da emergência dos próprios temas, tais como a Pedagogia Queer, a imigração, revelando a face de uma seção pulsante que busca provocar o pensar e a reflexividade.

A professora Célia Linhares (2007), fundadora deste periódico, nos brindou com o conceito de experiências instituintes que afirma serem tais experiências aquelas em que os autores confrontam não só inércias, estratificações instituídas e esforços de permanência e concentração de privilégios, mas outros empenhos que tendem a alterar, diferir e criar uma outra escola, em articulação com uma outra sociedade, também mais justa, mais amorosa, mais includente e mais plural.

A seção Experiências Instituintes nos convida a seguir um processo de construção de uma escola outra, para pensarmos uma concepção outra de formação de professores que rompa com o espaço e o tempo que costumam organizar e direcionar as práticas instituidas nos modelos usuais de aula (. Nessa perspectiva de conhecer experiências instituintes somos levadas a visitar o movimento zapatista, cuja proposta visa a descolonização radical da educação, por meio de processos que geram autonomia. Conhecemos também as experiências de professoras e professores que buscam, numa perspectiva inclusiva de educação, tramar linhas das ciência, das artes e da história no tecido do conhecimentos, caminhos outros de pensar e fazer educação por linhas que fogem aos modelos disciplinares.

Temos neste número vinte e oito artigos, avaliados por uma equipe altamente qualificada e que, em diálogo com o escopo de nossa publicação, vem se enlaçando, de forma resistente, nas guerrilhas contra os ataques que a educação pública e seus profissionais vêm sofrendo. Convidamos você a ler os artigos aqui publicados e a entrar nesta luta, que é de todos os que buscam uma educação emancipadora, em que caibam todos por inteiro.

Dagmar Mello e Silva Érika Leme Léa da Cruz

Nazareth Salluto

Rejany dos S. Dominick

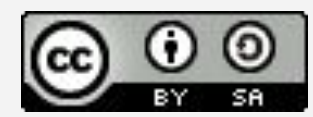
Sandra Maciel de Almeida

Walcéa Barreto Alves
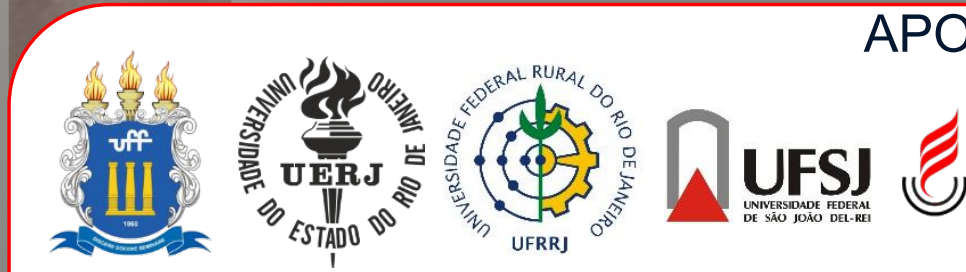

APOIOS
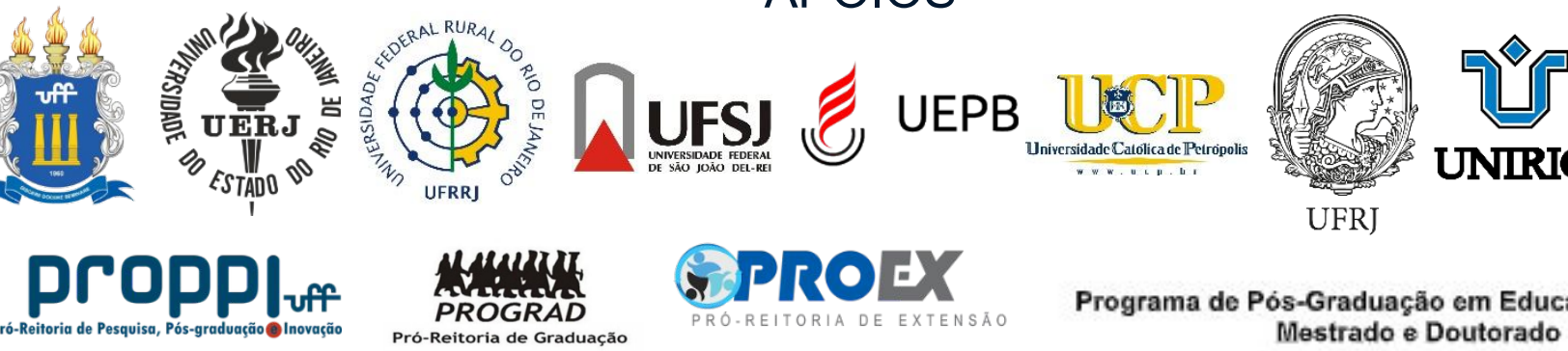

UFRJ

Programa de Pós-Graduação em Educação 1971-2018 Mestrado e Doutorado 